\title{
Shifting the Tide: Transit-Oriented Development and Active Transportation Planning in Los Angeles
}

\author{
Forrest Chamberlain \\ MCRP 2015, Cal Poly San Luis Obispo.
}

\author{
William Riggs \\ PhD; Assistant Professor, CRP Department, Cal Poly San Luis Obispo.
}

\begin{abstract}
Chamberlain and Riggs present an overview of the historical context of automobile dependency in Los Angeles, the current transit-oriented development strategies underway, and the planning and implementation of Complete Street strategies. The discussion illustrates how the city is using these strategies to reduce greenhouse gas emissions and the impacts of climate change.
\end{abstract}

\begin{abstract}
os Angeles has the reputation of an auto dependent city. LHistorically, much of the region was developed as suburban sprawl, designed to accommodate automobile use. Although the region is served by a robust public transportation system, the majority of the population commutes by automobile (SCAG, 2012a). As a result of excessive automobile use, the region has long suffered from poor air quality, traffic congestion, unsafe streets, and environmental degradation. Sprawling development patterns have diminished the environmental quality of natural areas on the urban fringe. Automobile use has exacerbated the region's greenhouse gas emissions. In recent years, issues around climate change have become paramount for cities throughout the world. Because a major source of greenhouse gas emissions comes from automobile travel, cities have a responsibility to reduce emissions in their jurisdictions by shifting travel behavior. This typically involves limiting development to primarily occur in areas accessible by public transit, and by accommodating alternative modes of travel through the design of the transportation system.
\end{abstract}

The Los Angeles region has made significant headway in reversing sprawl and automobile use. Encouraging greater land use densities around transit stations, coupled with investments to active transportation systems, has become both city and regional strategies to reduce greenhouse gas emissions. A dense, transit-oriented Los Angeles is a bold new vision. The following paper presents an overview of the historical context of automobile dependency in Los Angeles, the current transitoriented development strategies underway, and the planning and implementation of Complete Street strategies.

\section{Sprawl and Auto Dependency in Los Angeles: The Historical Context}

\section{Streetcar Suburb}

Automotive use has been the primary factor that has shaped the urban form of Los Angeles. Before the private automobile gained popularity, Los Angeles was served by an extensive streetcar system, established in the late 1800 s by powerful real estate moguls. These entrepreneurs not only constructed the streetcar lines themselves, but also residential neighborhoods adjacent to streetcar lines (Jackson, 1985). The streetcar system thus enabled Los Angeles to grow outward from the downtown core, fostering the development of "streetcar suburbs" that would eventually set the momentum for the region's decentralization and sprawl (Bottles, 1987; Jackson, 1985; Longstreth, 1998).

From the late 1880s until the 1920s, the streetcar was the dominant mode of travel for commuters in the Los Angeles region (Bottles, 1987; Longstreth, 1998). During this time real estate development was closely associated with the streetcar - most development in the region occurred around streetcar lines (Longstreth, 1998). The streetcar suburb is not specific to Los Angeles - this pattern of development characterized historic development trends in virtually every major American city prior to the mass adoption of the automobile. However, few other American cities were altered as dramatically as Los Angeles from the automobile.

\section{The Early Proliferation of Automobile Use}

Private automobile use caught on quickly in the Southern California region. The 1920s marked a departure from the streetcar to the automobile as the dominant mode of travel. From 1918 to 1923 automobile registration in Los Angeles County had increased by fourfold (Bottles, 1987).

By 1925 , there was approximately one car per 1.6 persons in the region, a level of automobile density that the rest of the nation wouldn't reach until the late 1950s (Davis, 1992; Bottles, 1987). As a result of increased automobile use, residential development became more closely associated with the automobile than the streetcar. To keep up with the demand for 
housing, developers had two options: increase density in builtup areas around railways, or construct housing on the urban periphery, often in areas distant from existing streetcar lines (Longstreth, 1998). Developers typically chose the second option. Post 1920, residential development and automobile use had a "symbiotic relationship" resulting in a high percentage of low-density neighborhoods consisting of single-family houses located increasingly further away on the urban periphery (Longstreth, 1998).

\section{Automobile Domination}

The number of people commuting by automobile eventually grew to outnumber the number using public transportation (Longstreth, 1998). As automobile use proliferated, there was an increasing conflict between streetcars and motorists for use of the right-of-way. Automobiles exacerbated traffic congestion in downtown Los Angeles, an area that had already been struggling with streetcar congestion (Bottles, 1987; Longstreth, 1998). To curb congestion, the city council passed a rigid no parking law in downtown that was met with heavy opposition and protest, forcing the council to quickly repeal the law (Bottles, 1987). This was the first of many legislative decisions that entrenched the automobile as the integral component of the regional transportation system. Between 1920 and 1950, highways were constructed, streets were widened, and streetcar lines were demolished, all to accommodate the automobile (Longstreth, 1998; Bottles, 1987; Jackson, 1985). By 1944 the streetcar system was scarcely used (Bottles, 1987).

The prioritization of automobiles in the transportation system allowed automobile use to increasingly grow during this time period. As a result, Los Angeles has a whole became more decentralized and suburban in character. Downtown's "central place monopoly" (Davis, 1992: 118) was superseded by new automobile-oriented commercial districts located away from the urban core (Longstreth, 1998; Davis, 1992; Bottles, 1987). Low-density sprawl has largely characterized the region's development history (Longstreth, 1998). Both the city and region now primarily consists of suburban areas highly dependent on the automobile. Although suburbanization and decentralization was exacerbated by the automobile, the city had been following this trajectory since the turn of the 20th century when streetcars were the dominant mode of travel. Mobility in a city as decentralized as Los Angeles requires some form of vehicular travel, whether it is by public transit or the automobile. As Bottles (1987: 14) describes it, Los Angeles has "never existed as a true walking city".

\section{Transit Oriented Development}

The long-term development of Los Angeles as an automobile oriented city has had profoundly negative impacts on the environment and public health. However, there has been recent momentum in creating a more environmentally friendly and healthy region through transit-oriented development strategies.
Densely populated cities with strong access to public transit emit less carbon than sprawling, low-density cities. A 2006 study found that the most densely populated cities have less private automobile use and lower greenhouse gas emissions per capita than the majority of cities in the United States (Dodman, 2009). Increasing land use densities close to transit is considered as a key strategy to reduce greenhouse gas emissions. However, it is also simply considered good urbanism. Compact communities with strong access to transit have greater access to jobs and services than sprawling, low-density cities.

Los Angeles has a robust transit system in place, yet is often characterized as a city that is inherently not transit-oriented. The existing transit network, coupled with proposed investments, creates an enormous opportunity for a more transit-oriented region. $97 \%$ of residents in the SCAG region live within two miles of an existing transit station, and $22.5 \%$ of jobs in Los Angeles County are within a half-mile of existing or proposed transit stations (SCAG, 2012a; Center for Transit-Oriented Development, 2010). Land use densities and intensities can be increased around Metro stations throughout the region. A 2010 study found that much of the land uses around transit stations consist of vacant and underutilized properties, including small parcels that do not comfortably accommodate development (Center for TransitOriented Development, 2010). The same study concluded that local governments need to better coordinate their land use and implementation strategies to better accommodate commercial and high-density residential development in station areas. This will be a challenge in meeting state goals to reduce greenhouse gas emissions from automobiles.

\section{$\underline{\text { SB } 375 \text { and Sustainable Communities Strategy }}$}

The Sustainable Communities and Climate Protection Act (SB 375) was enacted in 2008 with the intent of supporting California's climate action goals to reduce greenhouse gas emissions from vehicle use (California Air Resources Board, 2014). SB 375 requires each urbanized region to prepare a Sustainable Communities Strategy (SCS), which coordinates land use and transportation planning efforts to reduce vehicles miles travelled over a 25 year time period (California Air Resources Board, 2014). Local governments within each region are incentivized to coordinate planning efforts with the SCS, typically because of opportunities for state and federal funding sources (Logan, 2013).

In 2012, the Southern California Association of Governments (SCAG) adopted a \$525 billion Regional Transportation Plan (RTP) and Sustainable Communities Strategy for the six counties and 191 cities it represents (Logan, 2013; SCAG, 2012). The plan outlines a regional transportation plan and land use plan to meet GHG reduction targets consistent with SB 375 (SCAG, 2012). The transportation component proposes a variety of improvements to the region's multimodal transportation system, including the expansion of the system to areas where growth is appropriate (SCAG, 2012). The land use component proposes 
that growth should be prioritized in areas well served by public transportation, particularly around transportation nodes and corridors (SCAG, 2012).

\section{SCAG RTP/SCS Overview: Land Use}

Employment and housing growth is encouraged in the RTP/SCS to primarily occur within the region's designated High-Quality Transit Areas (HQTA) and Transit Priority Areas (TPA) (SCAG, 2012). HQTAs are described as walkable areas located within a half-mile radius of local and regional transit corridors with frequent service (15 minutes or less) during peak commute hours (SCAG, 2012). TPAs are areas within a half-mile of a major existing or planned transit station (SCAG, n.d) where transit-oriented development projects are provided with CEQA exemptions and alternative analysis of transportation impacts (OPR, 2014).

Not all HQTAs and TPAs in the region are targeted for growth (SCAG, 2012). Under SB 375 an SCS cannot mandate land use and General Plan policies at the local level. It is rather intended to provide cities and counties with land use, transportation, and housing policy guidance on how to help the region achieve greenhouse gas reduction targets (SCAG, 2012; California Air Resources Board, 2014). SCAG RTP/SCS land use policies were heavily influenced by local land use policies (SCAG, 2012). Many localities within the SCAG region have robust transit-oriented development land use policies and programs in place, while others continue to encourage auto-oriented development (SCAG, 2012). Development within the region will likely occur outside of HQTAs.

\section{Local Transit-Oriented Land Use Planning}

In addition to the RTP/SCS, Metro and the City of Los Angeles have a number of transit-oriented development supportive policies, programs and strategies in place. Although areas around transit stations are mostly out of Metro's jurisdiction, they encourage local governments to enact land use policies that incentivize transit-oriented development through policy guidance, technical support, and grant funding (Los Angeles County Metropolitan Transportation Authority, 2015; Center for Transit-Oriented Development, 2010). Metro administers a TOD Planning Grant Program designed to facilitate the adoption of local land use regulations that supports transit oriented development, and a Joint Development Program that collaborates with developers to construct transit-oriented developments on properties owned by Metro (Los Angeles County Metropolitan Transportation Authority, 2015; Los Angeles County Metropolitan Transportation Authority, 2015a).

Transit-oriented development is encouraged in the Framework Element of the Los Angeles General Plan and in Community Plans. The General Plan Framework Element sets forth a longterm growth strategy that guides the update of community plans and otherGeneral Plan elements (Los Angeles Department of City Planning, 2001c). The Framework Element has defined overlay zones that encourages different development types, densities, and intensities. Dense transit-oriented development is primarily encouraged in the Downtown Center, Regional Center, and Community Center categories, most of which are located close to transit stations and lines.

Community Plans are the primary tool used by the city to support transit-oriented growth (Center for Transit-Oriented Development, 2010, p. 84). The majority of Community Plans support transit-oriented development, while the Southeast and South LA Community Plans specifically support the RTP/ SCS. Community Plans generally propose zone changes to encourage mixed-use development of greater density and intensity in areas close to transit (Los Angeles Department of City Planning, 2001b; 2012a; 2012b; 2012c; 2013; 2014a; 2014; 2014c). In addition, the city is in the process of finalizing the Community Plan Implementation Overlay (CPIO), a land use tool that will bolster the implementation of Community Plan proposals. The CPIO will incentivize transit-oriented development through flexible zoning requirements and a streamlined review process (Center for Transit-Oriented Development, 2010, p. 85; Sulaiman, 2015).

\section{Development Permit Analysis}

The majority of the City of Los Angeles is considered a High Quality Transit Area. These areas have frequent access to some form of transit, whether it is light rail, bus, BRT, or subway. Within the City of Los Angeles, an optimal transitoriented development strategy involves the prioritization of development specifically within a half-mile radius of Metro stations. Development in these areas is appropriate for several reasons. First, a half-mile radius is the standard transit station catchment area (average distance people are willing to walk to take transit) used in the United States, and it has come to represent the spatial extent of most transit-oriented development planning (Guerra, Cervero, \& Tischler, 2012). Second, SCAG and the City of Los Angeles encourage growth to occur in these areas. All areas within a half-mile radius of Metro rail stations in the City of Los Angeles have been designated by SCAG as both a HQTA and a TPA (Figure 1) (SCAG, n.d). The majority of locally designated higher-intensity land use districts (Downtown Center, Regional Center, Community Center) are located in these areas.

In a city as large as Los Angeles, it is questionable whether or not transit-oriented development is being maximized in Metro station areas. To answer this question, a spatial analysis was used. Using ArcGIS, a half-mile buffer was placed around all existing Metro rail stations in the City of Los Angeles. New development permit data ranging from 2013 to 2015 was then added to ArcGIS to examine how many new buildings were permitted in Metro station areas. Between 2013 and 2015, only a very small number of development projects were permitted in transit-rich areas. The vast majority (95\%) of new development has been permitted in areas located outside of a half-mile radius of Metro stations (Table 1). This supports the Center of Transit Oriented Development's conclusion that the City of Los Angeles can 


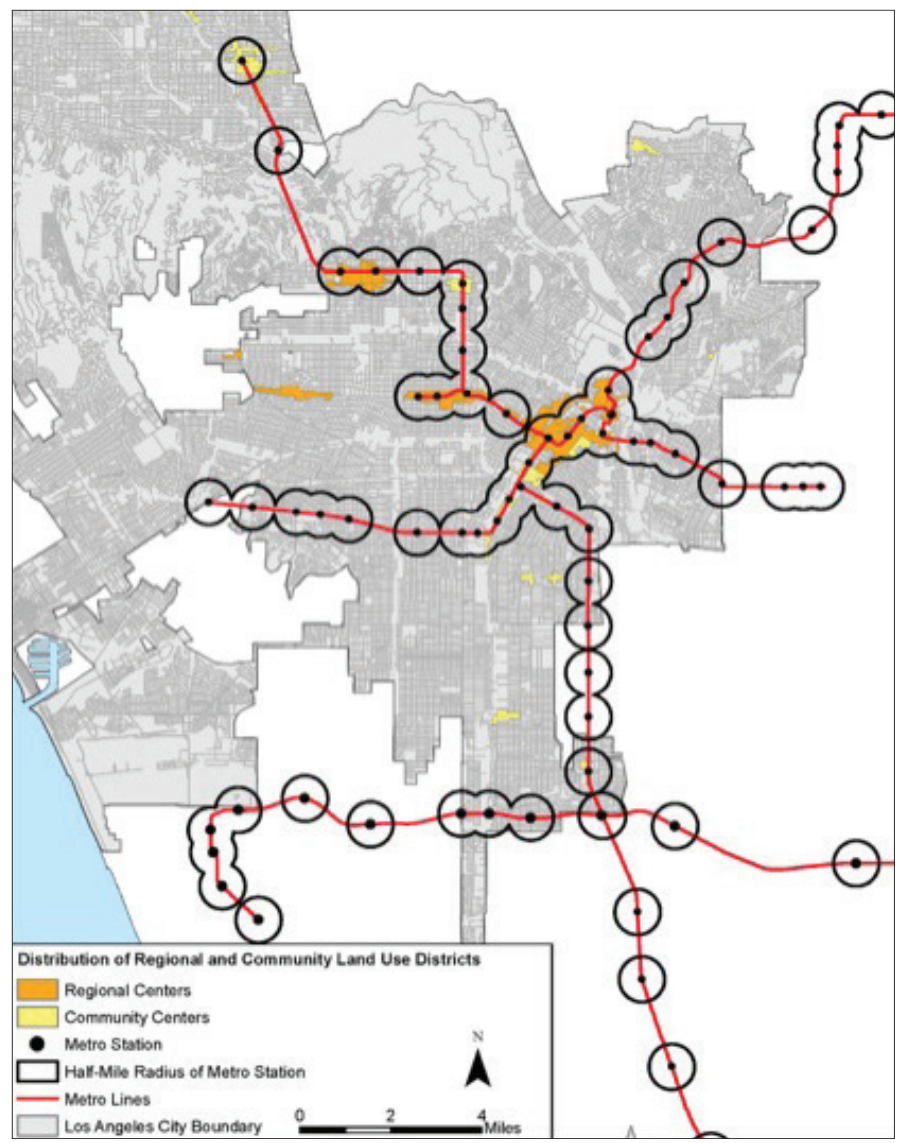

Figure 2: Map of Regional and Community Land Use Districts.

In order to successfully reduce automobile trips, transit-oriented development must be paired with a public realm conducive to other modes of transportation. According to Hank Dittmar, president of the Great American State Foundation, many transit-oriented neighborhoods are designed for automobile dependency, making them transit-adjacent rather than transitoriented (Tumlin \& Millard-Ball, 2003). Complete Streets are one strategy that can help to reduce automobile use in areas served by transit. Research shows that transit commute shares increase with the implementation of pedestrian-oriented design treatments in neighborhoods around rail stations. Research also shows that an increase in lineal miles of bicycle facilities contribute to a growth in accessing rail stations by bicycle (Cervero, Caldwell \& Cuellar, 2012). Complete streets will be essential to curb automobile use in Los Angeles, a region that will experience substantial transit investments in the next several decades.

\section{$\underline{A B} 1358$ and SB 375}

Enacted in 2008, the Complete Streets Act (AB 1358, 2008) requires cities and counties to incorporate Complete Streets principles into their circulation element when performing General Plan updates (AB 1358, 2008; SCAG, 2012). These

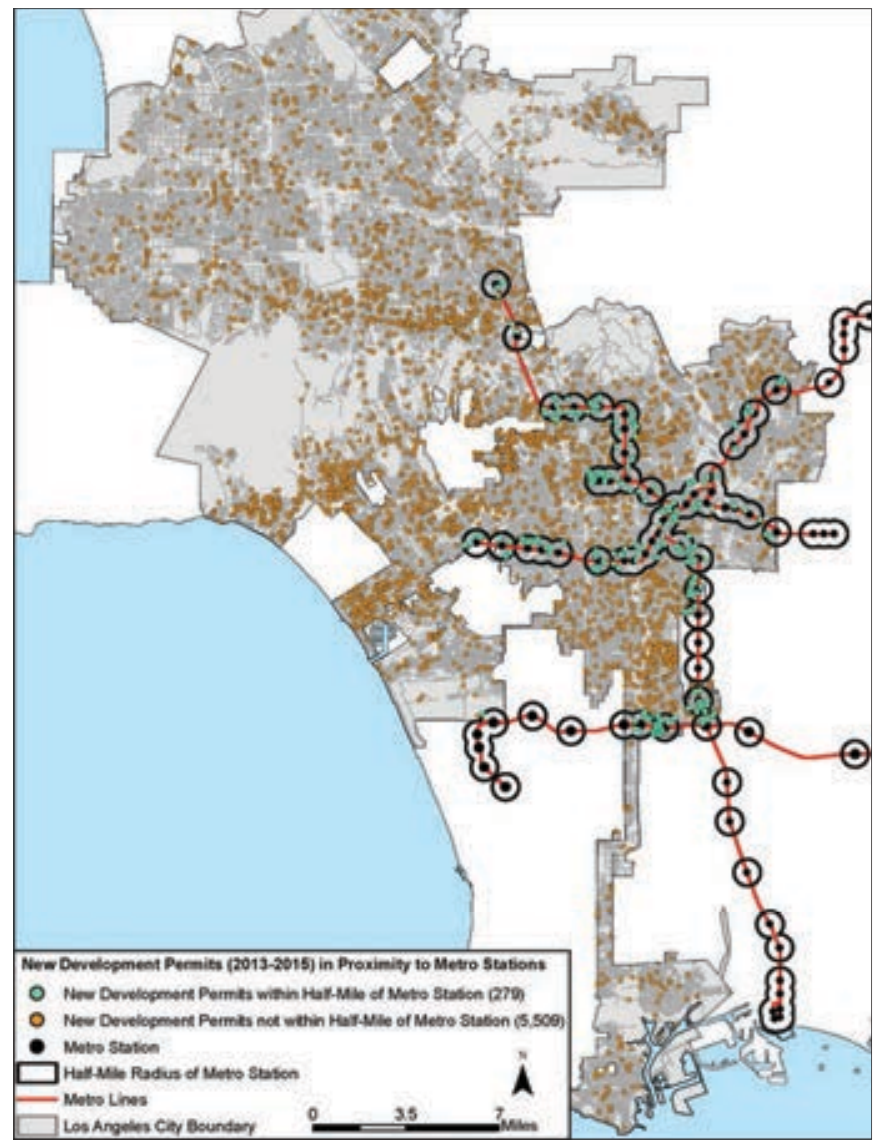

Figure 3: Proximity of New Development Permits (2013-2015) to Transit Stations.

principles are intended to foster a multimodal transportation network that accommodates all users of streets - pedestrians, cyclists, and motorists. Prior to the adoption of AB 1358, there were no state laws requiring localities in California to incorporate Complete Streets or active transportation principles into their circulation elements. When paired with SB 375, these two bills have the potential to advance transitoriented growth in a way that is largely unprecedented. Both are considered as landmark planning legislation in California.

Although there is no explicit language in SB 375 or $A B$ 1358 stating that the two bills should be linked during implementation, they both share similar end goals to reduce vehicle miles travelled (SB 375, 2008; $A B$ 1358, 2008). SB 375 approaches this goal by encouraging transit-oriented development, while AB 1358 approaches this goal by encouraging active transportation. In this regard, the two are fundamentally linked. Land use changes and transportation investments will go a long way in reducing greenhouse gas emissions. However, $A B 1358$ provides the impetus for the mode shift required to reduce private vehicle use. An optimal planning strategy to reduce vehicle miles travelled requires both approaches. 


\section{SCAG RTP/SCS Overview: Active Transportation}

Complete Streets and active transportation is a key cornerstone of the Southern California Association of Government's Regional Transportation Plan and Sustainable Communities Strategy (RTP/SCS). The RTP/SCS states that a mode shift to walking and bicycling will be essential to reduce greenhouse gas emissions and congestion (SCAG, 2012a). SCAG has adopted strategies in the RTP/SCS to achieve four overarching goals: 1) increase dedicated funding for bicycle and pedestrian infrastructure; 2) increase accommodation and planning for bicyclists and pedestrians; 3 ) increase transportation options, particularly for trips less than three miles, and; 4) significantly decrease bicycle and pedestrian fatalities and injuries (SCAG, 2012a). Similar to the land use component of the RTP/SCS, SCAG will primarily play an advisory role to local governments in an effort to support Complete Streets and active transportation in the region. However, SCAG will allocate funding to local governments to plan and implement Complete Streets in their jurisdictions (SCAG, 2012).

The RTP/SCS has allocated $\$ 6.7$ billion to engineering, enforcement, and education strategies related to active transportation and Complete Streets (SCAG, 2012). Funding is specially allocated to support such strategies near transit stations and schools to reduce vehicle trips and to improve the safety and desirability of active transportation modes (SCAG, 2012). The $\$ 6.7$ billion of funding does not include locally funded projects or large development project that involve the construction of bicycle and pedestrian facilities. When factoring in local expenditures, the region is expected to spend more than $\$ 10$ billion on active transportation investments by 2035 (SCAG, 2012a).

\section{Local Active Transportation Planning}

Localities within the SCAG region have proposed and implemented a number of active transportation and Complete Streets projects. The draft Los Angeles County Bicycle Master Plan, released in 2011, calls for the development of a comprehensive, 695 mile network of bicycle facilities (SCAG, 2012a). Metro's Long Range Transportation Plan proposes the development of regional bicycle trail projects throughout the region. Metro has also created an initiative to provide an inventory of existing and proposed bicycle facilities, and an estimation of expenditures for such facilities (SCAG, 2012a). In addition, Metro's Complete Streets Policy has ranked higher than any region in California by Smart Growth America, who ranked Complete Streets policies and programs in the United States adopted in 2014 (Curry, 2015).

Metro's draft Complete Streets Policy supports existing planning efforts and proposes new projects. The Metro Complete Streets policy is intended to support these efforts by providing guidance and funding to local agencies (Los Angeles County Metropolitan Transportation Authority, 2014). Metro is particularly interested in the implementation of Complete Streets on "first/last" streets used to get to and from transit stations.
Metro further bolstered this effort through the draft First Last Mile Strategic Plan (2013) a set of planning guidelines with the goal to improve active transportation accessibility to Metro stations(Los Angeles County Metropolitan Transportation Authority, 2014a). The guidelines provide localities with examples of design treatments that can be implemented to improve active transportation on street segments located close to Metro stations. Because portions of these segments are out of Metro's jurisdiction, the Complete Streets policies and guidelines are primarily meant to advise localities (Los Angeles County Metropolitan Transportation Authority, 2014a). Metro has also proposed to establish active transportation improvements to their transportation system, including bicycle/pedestrian facilities and amenities at Metro stations (Los Angeles County Metropolitan Transportation Authority, 2014).

The draft 2014 update of the Circulation Element of the City of Los Angeles General Plan, referred to as "Mobility 2035", strongly emphasizes the incorporation of Complete Streets principles in the transportation system. Three of the nine key policy initiatives explicitly address Complete Streets and active transportation. These policy initiatives include the establishment of new Complete Streets standards, the promotion of "first mile-last mile" connections, and the expansion of the role of the street as public space (Los Angeles Department of City Planning, 2014e). The element also proposes the establishment of areas prioritized for pedestrian improvements, the development of an interconnected bicycle network, and the enhancement of multi-modal transportation services in areas close to transit stations(Los Angeles Department of City Planning, 2014e). Mobility Plan 2035 has yet to be adopted. As Linton (2015) points out, the plan serves as a departure to auto-centric character of Los Angeles, to "an emerging multi-modal Los Angeles that embraces walking, bicycling, using transit, and driving".

In 2011, the Downtown Los Angeles Neighborhood Council (DLANC) formed the Complete Streets Working Group to implement design treatments aimed to improve Downtown's cycling and pedestrian environment (Downtown Los Angeles Neighborhood Council, n.d.). According to their website, the DLANC Working Group has primarily focused on the development of bicycle facilities and parklets. The website does not mention traffic calming strategies, education strategies, and enforcement strategies. The DLANC Working Group has been responsible for the implementation of Downtown Los Angeles's first bicycle lane along a segment of Spring Street, as well as bicycle lanes on two more road segments (Downtown Los Angeles Neighborhood Council, n.d.). A 40\% increase in bicycle ridership along Spring Street was observed one year after installation of the bicycle lane (Downtown Los Angeles Neighborhood Council, n.d.).

\section{Conclusion}

The Los Angeles region has established aggressive transitoriented development and active transportation programs and plans. Although transit-oriented development programs 
are ambitious in their intent, it is somewhat unclear how effective they have been. In the last two years, only $5 \%$ of new development has been permitted within a half-mile radius of Metro stations in the City of Los Angeles. It is clear that the City could do more to prioritize development within these transitrich areas. If the region continues to develop in a low-density manor away from major transit stations, it will be difficult to achieve long-term greenhouse gas reduction targets.

When scanning Los Angeles's Complete Streets plans and programs, one could conclude that the region will be a haven for multi-modal transportation in the future. These plans are also ambitious, yet it is unclear how effectively they have been implemented. Further research is needed to examine the current state of Complete Streets implementation and active transportation in Los Angeles. For example, research could measures the increase in lineal miles of bicycle facilities over time. Monitoring the implementation of active transportation investments may be a more difficult task than development activity, as data is not as easily accessible as permit data. Overall, the City of Los Angeles has an enormous opportunity to reduce greenhouse gas emissions through land use changes and transportation investments.

\section{References}

AB 1358. 2008. California State Assembly.

Bottles, S. 1987. Los Angeles and the Automobile: The Making of the Modern City. Berkeley: University of California Press.

California Air Resources Board. 2014. Sustainable Communities. (C. E. Agency, Editor). Retrieved November 27, 2014, from http://www.arb.ca.gov/cc/sb375/sb375.html

Center for Transit-Oriented Development. 2011. Creating successful Transit-Oriented Districts in Los Angeles: A Citywide Toolkit for Achieving Regional Goals.

Cervero, R., Caldwell, B., \& Cuellar, J. 2012. Bike-and-Ride: Build it and They Will Come. Berkeley: UC Berkeley.

Curry, M. 2015. Smart Growth America Rates L.A. Metro Complete Streets Policy in Top Ten. Retrieved April 26, 2015, from Streets Blog (Web blog post): http://la.streetsblog. org/category/issues/complete-streets/

Davis, M. 1992. City of Quartz. London: Vintage.

Dodman, D. 2009. Blaming Cities for Climate Change? An Analysis of Urban Greenhouse Gas Emissions Inventories. Environment and Urbanization, 21 (1), 185-201.

Downtown Los Angeles Neighborhood Council. (n.d.). Complete streets for Downtown Los Angeles. Retrieved April 25, 2015, from: http://completestreets.dlanc.com/index. php
Jackson, K. 1985. Crabgrass Frontier: The Suburbanization of America. New York: Oxford University Press.

Logan, W. 2013. Implementing Sustainable Communities Strategies at the Municipal Level. Berkeley, CA: UC Berkeley.

Longstreth, R. 1998. City Center to Regional Mall: Architecture, the Automobile, and Retailing in Los Angeles, 1920-1950. Cambridge, MA: MIT Press.

Los Angeles County Metropolitan Transportation Authority. 2014. Metro Complete Streets Policy Draft. Retrieved 28 April 2015 from: http://media.metro.net/projects_ studies/sustainability/images/Draft_Complete_Streets_ Policy.pdf

Los Angeles County Metropolitan Transportation Authority. 2014a. First Last Mile Strategic Plan \& Planning Guidelines. Retrieved 29 April 2015 from: http://media.metro. net/docs/sustainability_path_design_guidelines.pdf

Los Angeles County Metropolitan Transportation Authority. (2015). Transit Oriented Development Planning Grant. Retrieved 3 May 2015 from: http://www.metro.net/projects/tod/Los Angeles County Metropolitan Transportation Authority. (2015a). Joint Development Program. Retrieved 3 May 2015 from: http://www.metro.net/projects/joint_dev_pgm/

Los Angeles Department of City Planning. n.d. Community Plans in Progress. Los Angeles: City of Los Angeles. Retrieved 5 December 2014 from: http://cityplanning.lacity.org/

Los Angeles Department of City Planning. n.d. Land use standards and typical development characteristics. Los Angeles: City of Los Angeles. Retrieved 5 December 2014 from: http://cityplanning.lacity.org/cwd/framwk/ chapters/03/tab31.htm

Los Angeles Department of City Planning. 2001a. The Framework Element of the Los Angeles General Plan. Chapter 3 - Land Use. Los Angeles, CA: City of Los Angeles.

Los Angeles Department of City Planning. 2001b. Wilshire Community Plan. Los Angeles: City of Los Angeles. Retrieved 5 December 2014 from: http://cityplanning. lacity.org/complan/central/wilpage.htm

Los Angeles Department of City Planning. 2001c. The Framework Element of the Los Angeles General Plan. Executive Summary. Los Angeles, CA: City of Los Angeles.

Los Angeles Department of City Planning. (2012a). Hollywood Community Plan. Los Angeles: City of Los Angeles. Retrieved 5 December 2014 from: http://cityplanning.lacity. org/complan/central/hwdpage.htm

Los Angeles Department of City Planning. (2012b). South Los Angeles Community Plan. Los Angeles: City of Los Angeles. Retrieved 5 December 2014 from: http:// cityplanning.lacity.org/ 
Los Angeles Department of City Planning. (2012c). Sylmar New Community Plan. Los Angeles: City of Los Angeles. Retrieved 5 December 2014 from: http://planning.lacity. org/cpu/Sylmar/SylmarDraftPlan.htm

Los Angeles Department of City Planning. 201. Draft West Adams-Baldwin Hills-Leimert New Community Plan. Los Angeles: City of Los Angeles. Retrieved 5 December 2014 from: https://sites.google.com/site/westadamsncp/home

Los Angeles Department of City Planning. 2014a. Southeast LoS Angeles Community Plan. Los Angeles: City of Los Angeles. Retrieved 5 December 2014 from: http://cityplanning. lacity.org/

Los Angeles Department of City Planning. 2014b. Boyle Heights New Community Plan Draft Goals and Policies. Los Angeles: City of Los Angeles. Retrieved 5 December 2014 from: https://sites.google.com/site/boyleheightsncp/

Los Angeles Department of City Planning. 2014c. Draft San Pedro New Community Plan. Los Angeles: City of Los Angeles. Retrieved 5 December 2014 from: https://sites.google. com/site/sanpedrocommunityplan/draft-plan-outline

Los Angeles Department of City Planning. 2014d. L.A Rising - how the Adaptive Reuse Ordinance Transformed Downtown Los Angeles. Unpublished document. Los Angeles, CA.

Los Angeles Department of City Planning. (2014e). Mobility Plan 2035. Los Angeles, CA: City of Los Angeles.

SB 375. 2008. California State Legislature.

SCAG. (2012a). 2012-2035 Regional Transportation Plan/ Sustainable Communities Strategy (RTP/SCS). Active Transportation Appendix. Retrieved 26 April 2015 from: http://rtpscs.scag.ca.gov/Pages/2012-2035-RTP-SCS.aspx

SCAG. 2012.2012-2035 Regional Transportation Plan/Sustainable Communities Strategy (RTP/SCS): Towards a Sustainable Future. Retrieved 12 November 2014 from: http://rtpscs. scag.ca.gov/Pages/2012-2035-RTP-SCS.aspx

SCAG. (n.d). DRAFT SB 743 - Transit Priority Areas (TPAs).

Sulaiman, S. (2015). Your Moment of City-Planning Zen: Lulu Guides you through the Community Plan Implementation Overlay Tool. Retrieved May 3, 2015, from Streetsblog (Web blog post): http://la.streetsblog.org/2015/03/20/your-moment-of-city-planning-zen-lulu-guides-you-through-thecommunity-plan-implementation-overlay-tool/

Tumlin, J., \& Millard-Ball, A. 2003. How to Make Transit-Oriented Development Work. Planning Magazine, May 2003. 